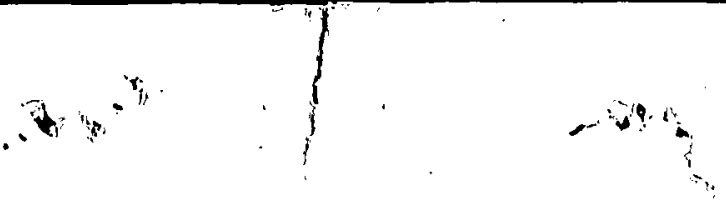

PURDUE UNIVERSITY

Department of Chemistry

Lafayette, Indiana

AEC Contract No. AT(11-1)-1505

A Test of the Independence Hypothesis by Angular

Distribution Measurements

N. T. Porile

D. M. Montgomery

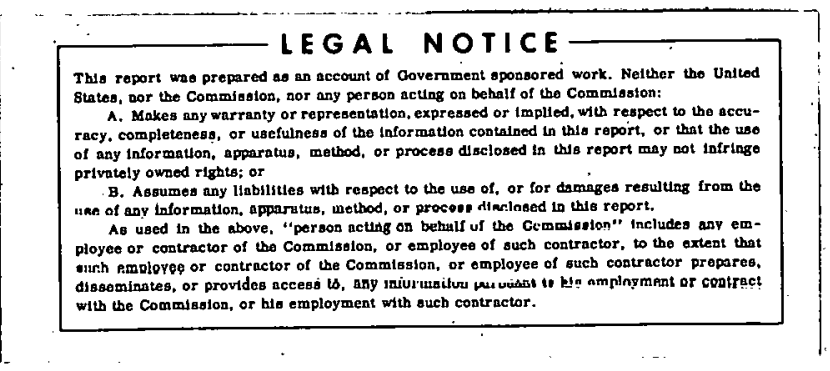

October 20, 1969

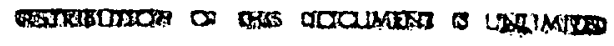
$\div$

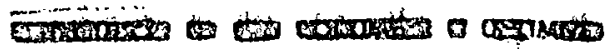




\section{DISCLAIMER}

This report was prepared as an account of work sponsored by an agency of the United States Government. Neither the United States Government nor any agency Thereof, nor any of their employees, makes any warranty, express or implied, or assumes any legal liability or responsibility for the accuracy, completeness, or usefulness of any information, apparatus, product, or process disclosed, or represents that its use would not infringe privately owned rights. Reference herein to any specific commercial product, process, or service by trade name, trademark, manufacturer, or otherwise does not necessarily constitute or imply its endorsement, recommendation, or favoring by the United States Government or any agency thereof. The views and opinions of authors expressed herein do not necessarily state or reflect those of the United States Government or any agency thereof. 


\section{DISCLAIMER}

Portions of this document may be illegible in electronic image products. Images are produced from the best available original document. 


\title{
A Test of the Independence Hypothesis by Angular Distribution Measurements*
}

\author{
D. M. Montgomery ${ }^{+}$and N. T. Porile \\ Department of Chemistry, Purdue University \\ Lafayette, Indiana 47907
}

\begin{abstract}
Angular distribution measurements of ${ }^{137 \mathrm{~m}} \mathrm{Ce}$ and ${ }^{137 g} \mathrm{Ce}$ from the reactions ${ }^{136} \mathrm{Ba}\left({ }^{4} \mathrm{He}, 3 n\right)$ and ${ }^{137} \mathrm{Ba}\left({ }^{3} \mathrm{He}, 3 n\right)$ have been made over the energy range from 33.3 to $43.6 \mathrm{MeV}$ and from 20.3 to $32.5 \mathrm{MeV}$, respectively. The results have been analyzed to give the average total kinetic energy of the neutrons and photons emitted in the reactions. Comparison of these quantities at the same excitation energy and angular momentum of the compound nuclei shows that they are equal within the limits of error and thereby confirms the independence hypothesis. The observed differences in the average photon energies for reactions leading to ${ }^{137 \mathrm{~m}} \mathrm{Ce}$ and

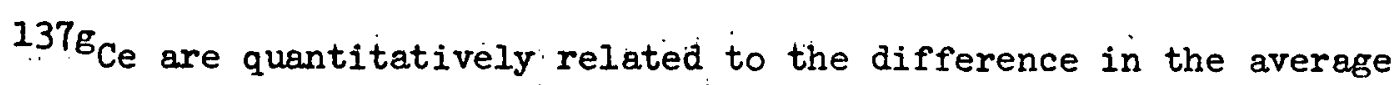
angular momentum of compound nuclei leading to each isomer.
\end{abstract}

\footnotetext{
* Supported by the U: S. Atomic Energy Commission

tSubmitted in partial fulfillment of the requirements for the Ph.D. degree in the Department of Chemistry, Purdue University.
} 


\section{Introduction}

In the preceding paper ${ }^{1}$ it was shown that the ${ }^{136} \mathrm{Ba}\left({ }^{4} \mathrm{He}, 3 n\right)$ and ${ }^{137} \mathrm{Ba}\left({ }^{3} \mathrm{He}, 3 \mathrm{n}\right)$ reactions proceed via compound nucleus formation at intermediate energies. The compound nuclear character of these reactions was established by average range measurements of the ${ }^{137} \mathrm{Ce}$ recoils and corroborated by excitation function and isomer ratio measurements.

Since both reactions involve the formation of the same compound nucleus they can be used to test the independence hypothesis, which states that the decay of a compound nucleus is independent of its mode of formation and depends only on its excitation energy and angular momentum. Previous tests of the independence hypothesis have involved the measurement of excitation functions ${ }^{2,3}$ and charged particle spectra. 4 The present work is based on the measurement of the angular distributions of the ${ }^{137 m, g_{C e}}$ recoil nuclei. The angular distribution results can be analyzed by methods described elsewhere ${ }^{5,6}$ to give values of the average total kinetic energy of the emitted neutrons $T_{n}$ and the average total energy -dissipated by photons $T_{\gamma}$. If the decay of the compound nucleus is independent of its mode of formation, there should be no differences in the $\mathrm{T}_{n}$ or $\mathrm{T}_{\gamma}$ values from the ${ }^{3} \mathrm{He}$ and ${ }^{4} \mathrm{He}$ reactions provided the comparison is made at the same excitation energy and angular momentum of the compound nucleus. The study of reactions involving isomer formation is particularly useful in connection with this requirement since, as will be shown later, it permits the equalization of both these quantities in the formation of the low-spin product. Measurement of the angular distribution of isomeric products also gives information on the effect of angular momentum on the deexcitation process. 
In this paper we present our results from a comprehensive study of the angular distributions of ${ }^{137 m, g_{\mathrm{Ce}}}$ from the $\left({ }^{4} \mathrm{He}, 3 n\right)$ and $\left({ }^{3} \mathrm{He}, 3 \mathrm{n}\right)$ reactions over the compound nucleus excitation energy range from 33.7 to $46.8 \mathrm{MeV}$.

\section{Experimental}

The experimental procedure and apparatus for angular distribution studies have been described in previous reports from this laboratory. 7,8 Thin targets are irradiated in an evacuated chamber. The product nuclei recoil out of the target in a forward cone and are stopped by a circular catcher foil placed a known distance from the target. The catcher foil is cut into concentric rings each of which corresponds to a particular angular interval and the radioactivity of each ring is assayed following chemical separation of cerium.

The targets were prepared from enriched ${ }^{137} \mathrm{Ba}(89.6 \%)$ and ${ }^{136} \mathrm{Ba}$ $(97.2 \%) .^{9}$ Thin targets, ranging from 5 to $15 \mu \mathrm{gm} / \mathrm{cm}^{2}$, were prepared by molecular plating. 10 Fifty microliters of a solution containing 10 to $20 \mathrm{\mu gm}$ of $\mathrm{Ba}\left(\mathrm{NO}_{3}\right)_{2}$ were placed in a cell containing approximately $20 \mathrm{ml}$ isopropyl alcohol. A rotating platinum electrode assembly was used to deposit $\mathrm{Ba}\left(\mathrm{NO}_{3}\right)_{2}$ on $1 \mathrm{mil} \mathrm{Ml}$ foil of high purity (99.999\%). The Al foil served as the cathode and the cell was operated at $250 \mathrm{~V}$ for approximately 1 hour.

The bombardments were carried out in the ${ }^{3}$ He and 4 He ion beams of the Argonne National Laboratory 60-inch cyclotron. Irradiations lasted from 2 to 3 hours at beam intensities from 0.1 to $0.3 \mu \mathrm{mp}$. The beam was collimated before entering the chamber by 0.95 and $0.48 \mathrm{~cm}$ aperatures. 
An $0.32 \mathrm{~cm}$ collimator located just in front of the water cooled target holder further defined the beam. Before inserting the target foil, alignment experiments were performed to insure that the beam passed through the center of the target and catcher foils. The beam was degraded to the desired energy by placing AI foils in front of the collimators. The ${ }^{3} \mathrm{He}$ and ${ }^{4} \mathrm{He}$ energies were calculated from the incident energy and an appropriate range-energy relationship. 11

The catcher foil consisted of the same high-purity aluminum as the target backing. After irradiation it was cut into 10 concentric rings and $\mathrm{Ce}$ was separated from each foil by a previously described procedure. ${ }^{1}$ The ${ }^{137 \mathrm{~m}, g_{C e}}$ disintegration rates were determined with thin $\operatorname{NaI}(\mathrm{TI})$ detectors connected to single channel analyzers set to accept the La and Ce $K-x$-rays, as described in further detail in the preceeding paper. ${ }^{1}$ The data were analyzed by a least squares program described in a previous report ${ }^{12}$ from this laboratory.

The effects of target thickness and collimator size on the angular distribution were investigated for the $\left({ }^{4} \mathrm{He}, 3 n\right)$ reaction. The target thickness effect was determined by irradiating targets of $5.5 \mu \mathrm{gm} / \mathrm{cm}^{2}$ and $10.0 \mu \mathrm{gm} / \mathrm{cm}^{2}$ at 39.2 and $39.0 \mathrm{MeV}$ bombarding energy, respectively, with an $0.32 \mathrm{~cm}$ collimator at the target. The collimator effect was studied by irradiating a $12.0 \mathrm{\mu gm} / \mathrm{cm}^{2}$ target with an $0.16 \mathrm{~cm}$ collimator at $39.1 \mathrm{MeV}$. The resulting angular distributions of $137 \mathrm{~m}$ Ce are shown in Fig. 1. The various curves have been normalized to the same area. It is seen that there is no broadening of the angular distribution due to target thickness for the thin targets used in this experiment. The mean angles obtained for target thicknesses of $5.5 \mu \mathrm{gm} / \mathrm{cm}^{2}$ and $10.0 \mu \mathrm{gm} / \mathrm{cm}^{2}$ were $10.1^{\circ}$ and $10.0^{\circ}$, respectively. The ${ }^{137 g} \mathrm{Ce}$ angular distributions showed the same insensitivity to target thickness as those 
of ${ }^{137 m} \mathrm{Ce}$, The mean recoil angle of ${ }^{137 \mathrm{~m}} \mathrm{Ce}$ from the experiment with the $0.16 \mathrm{~cm}$ collimator was $10.8^{\circ}$. The widening-of the angular distribution for a smaller collimator is opposite to the expected effect and must be due to an experimental uncertainty for this particular bombardment. A subsequent ${ }^{13}$ test of the collimation effect using the same apparatus and similar experimental conditions showed that collimation effects on the angular distributions of ${ }^{137 m}, \mathrm{~g}_{\mathrm{Ce}}$ are negligible.

III. Results

The angular distribution data, which are available from the authors on request, were used to obtain for each reaction the values of the mean laboratory recoil angle, $\left\langle\theta_{L}\right\rangle$, and those of $\left\langle\tan ^{2} \theta_{L}\right\rangle$. The equations by which these quantities were calculated from the measured disintegration rates, $D_{i}$, are:

$$
\left\langle\theta_{L}>=\sum_{i} \cdot D_{i} \Delta \theta_{i}<\theta_{i}>/ \sum_{i} D_{i} \Delta \theta_{i}\right.
$$

and

$$
\left\langle\tan ^{2} \theta_{L}>=\sum_{i} D_{i} \Delta \theta_{i}<\tan ^{2} \theta_{i}>/ \Sigma D_{i} \Delta \theta_{i}\right.
$$

The summations are over the $i$ rings of the catcher foil, $\Delta \theta_{i}$ is the angular interval corresponding to the $i^{\text {th }}$ ring, and $\left\langle\theta_{i}\right\rangle$ and $\left\langle\tan ^{2} \theta_{i}\right\rangle$ are the mean values of these quantities for the ring in question.

The results are summarized in Table $I$. The uncertainties in the ${ }^{<\theta_{i}}>$ values are approximately $0.1^{\circ}-0.3^{\circ}$ and arise from the statistical uncertainty in the disintegration rates, as well as minor errors in the chemical yield determinations and alignment procedures. 
The mean angles are plotted as a function of the available energy, $\mathrm{E}_{\mathrm{cm}}+\mathrm{Q}$, in Fig. 2. The $\mathrm{Q}$ values were determined from the nuclidic masses compiled by Mattauch et al ${ }^{14}$ and $\mathrm{E}_{\mathrm{cm}}$ is the center of mass bombarding energy. The various trends displayed by these data are readily explainable. The gradual increase of $\left\langle\theta_{L}\right\rangle$ with energy airises from the fact that the recoil velocity due to neutron emission increases more rapidly with energy than the velocity of the compound nucleus. For a given value of the available energy the $\left\langle\theta_{L}\right\rangle$ from ${ }^{3} \mathrm{He}$ irradiations are some $3^{\circ}-5^{\circ}$ larger than those for ${ }^{4} \mathrm{He}$. This difference is merely a consequence of the larger forward momentum imparted to the compound nucleus in 4 He bombardments. The $\left\langle\theta_{I}>\right.$ of ${ }^{137 m_{C e}}$ are uniformly larger than those of ${ }^{137 g_{C e}}$, the difference at a given energy amounting to close to $1^{\circ}$. This difference reflects differences in the partition of the available energy between neutrons and photons and is discussed in more detail below.

\section{Discussion}

The experimental results may be analyzed to yield the values of $\mathrm{T}_{\mathrm{n}}$ and $\mathrm{T}$. The mean squared velocity imparted to the residual nucleus as a result of isotropic neutron evaporation $\left\langle v^{2}\right\rangle$ may be related ${ }^{6}$ to $\left\langle\tan ^{2} \theta_{I}>\right.$ by the expression

$$
\left\langle\tan ^{2} \theta_{L}\right\rangle=\sum_{n=1}^{\infty} \frac{2\left\langle V^{2 n}\right\rangle}{(2 n+1)} \underset{v_{C N}}{2 n}
$$

The quantity $v_{C N}$ is the velocity of the compound nucleus, obtained from the bombarding energy and conservation of momentum. In turn $\left\langle V^{2}\right\rangle$ is related ${ }^{5}$ to the average total kinetic energy of the emitted neutrons by

$$
\left\langle V^{2}\right\rangle=\frac{8 T}{\left(A_{T}+A_{b}+A_{R}\right)^{2}}
$$

where the masses of the target, bombarding, and product 
nuclei are denoted respectively by $A_{T}, A_{b}$, and $A_{R}$. Finally, $T_{\gamma}$ is obtained as the difference between the total available energy and $T_{n}$ :

$$
\mathrm{T}_{\gamma}=\left(\mathrm{E}_{\mathrm{cm}}+\mathrm{Q}\right)-\mathrm{T}_{\mathrm{n}}
$$

The values of $\left\langle V^{2}\right\rangle$ were calculated by solving Eq: 3 by an iteration procedure. Three terms in the expansion were required to obtain $\left\langle V^{2}\right\rangle$ within $1 \%$ accuracy. The use of more than one term requires the assumption that $\left\langle v^{2 n}\right\rangle=\left\langle v^{2}\right\rangle^{n}$.

The results of this analysis are summarized in Table 1 . The uncertainties in the values of $T_{n}$ and $T_{\gamma}$ were estimated from the differences in the results obtained from bombardments at approximately the same energy as well as the total statistical uncertainty of the counting data. The mean uncertainty is $0.2 \mathrm{MeV}$ for ${ }^{137 \mathrm{~m}} \mathrm{Ce}$ and $0.6 \mathrm{MeV}$

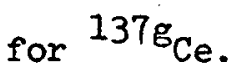

The validity of the independence hypothesis may be tested by comparing the values of $T_{n}$ or $T_{Y}$ derived for the two reactions at the same value of the available energy. Before presenting this comparison it is necessary to consider the differences in the angular momentum of the two systems. Since the reaction products are isomeric we are particularly interested in calculating the average angular momentum of those compound nuclei that deexcite to each isomeric otate, denuted by $\left\langle\mathrm{J}_{\mathrm{c}}^{\mathrm{m}}>\right.$ and $\left\langle\mathrm{J}_{\mathrm{c}}^{\mathrm{g}}\right\rangle$.

The isomer ratio program described in the preceding paper ${ }^{1}$ was used to perform this calculation. The basic steps of the calculation invulve the evaluation of the angular momentum distribution of the compound nucleus, the residual nucleus formed after the emission of each neutron, and that formed after the emission of each but the last 
$\gamma$-ray. At this point in the program the yield of excited nuclei vith

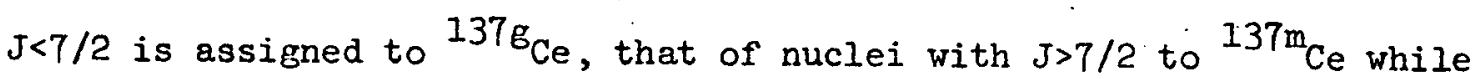
that of nuclei with $J=7 / 2$ is divided equally between the two products. Since the angular momenutm distribution of the compound nucleus is modified by neutron and photon emission and since the isomer assignment is based on this modified distribution, it is difficult to make a direct determination of $\left\langle\mathrm{J}_{c}{ }^{m}\right\rangle$ and $\left\langle\mathrm{J}_{c}{ }^{G}\right\rangle$. In order to check the sensitivity of these quantities to the deexcitation process, approximate values of $\left\langle\mathrm{J}_{\mathrm{c}}^{\mathrm{m}}>\right.$ and $\left\langle\mathrm{J}_{\mathrm{c}}^{\mathrm{g}}\right\rangle$ were determined by apportioning the angular momentum distribution between the two isomers in the manner outlined above at each step of the deexcitation process. The results for the ( $\left.{ }^{4} \mathrm{He}, 3 n\right)$ reaction at a compound nucleus excitation energy of $42.8 \mathrm{MeV}$ are summarized in Table II. The three entries refer, respectively, to the values obtained by apportioning the angular momentum distribution of the compound nucleus, that of the residual nucleus resulting from the emission of three neutrons, and that following the $\gamma$-ray cascade. It is seen that $\left\langle J_{c} g^{g}\right.$ is virtually independent of the method of calculation. On the other hand, the values obtained for $\left\langle J_{c}{ }^{m}\right\rangle$ decrease as the deexcitation process proceeds. This result is a consequence of the shift of the angular momentum distribution of the compound nucleus towards lower values by the emission of neutrons and photons. The values of $\left\langle J_{c} g_{\rangle}\right.$do not reflect this trend because the low spin of ${ }^{137 g_{C e}}$ restricts its formation to the lower end of the angular momentum distribution, whose shape is rather insensitive to the effect of neutron and photon emission. Of the three methods of calculating $\left\langle J_{c}{ }^{m}\right.$ it is 
clear that the first one overestimates its value while the third one underestimates it: Therefore method 2 was chosen as the best approximation to a calculation of $\left\langle J_{c} m_{>}\right.$. and $\left\langle J_{c} g\right\rangle$.

The results of this computation are plotted in Fig. 3 for both $3_{\mathrm{He}}$ and ${ }^{4} \mathrm{He}$ bombardments. It is seen that the same values of $\left\langle J{ }_{c} g_{c}\right.$ are obtained for both reactions. Therefore, if a comparis on of $T_{n}$ and $T_{\gamma}$ for ${ }^{137 g_{\mathrm{Ce}}}$ formation is made at the same excitation energy of the compound nuclei, the average angular momentum of the latter will also be equal. The $T_{n}$ and $T_{\gamma}$ values for the two reactions are plotted in Fig. 4. Within the limits of error, the results for $3_{\mathrm{He}}$ and ${ }^{4} \mathrm{He}$ bombardments can be seen to fall on the same curve. This finding confirms the independence hypothesis for the reactions leading to ${ }^{137 \mathrm{~g}_{\mathrm{Ce}}}$.

In the case of ${ }^{137 m}$ Ce formation Fig: 3 shows that $\left\langle\mathrm{J}_{c}{ }^{m}\right\rangle$ is larger for ${ }^{4} \mathrm{He}$ bombardments by 1 to $3 \mathrm{~h}$ units. One may therefore expect a difference in the $T_{n}$ or $T_{\gamma}$ values. The magnitude of this difference can be estimated on the assumption that the photon energy arises from the dissipation of the rotational energy of the compound nucleus. The rotational energy is obtained from the rigid rotor model as

$$
E_{\text {rot }}{ }^{m}=\frac{\left\langle J_{c}{ }^{m}\right\rangle\left(\left\langle J_{c}{ }^{m}\right\rangle+1\right) \hbar^{2}}{2-b_{r}}
$$

where $\vartheta_{r}$ is the rigid-body moment of inertia. The expected difference in $T_{n}$ or $T_{\gamma}$ values is then obtained as the difference between the rotational energies obtained for ${ }^{3} \mathrm{He}$ and ${ }^{4} \mathrm{He}$ bombardnent. This difference ranges from about $0.2 \mathrm{MeV}$ for $\left(\mathrm{E}_{\mathrm{cm}}+\mathrm{Q}\right)=6 \mathrm{MeV}$ to $0.6 \mathrm{MeV}$ for $\left(E_{\mathrm{cm}}+\mathrm{Q}\right)=20 \mathrm{MeV}$. 
The values of $T_{n}$ and $T_{\gamma}$ for reactions leading to ${ }^{137 m}$ Ce are shown in Fig. 5. The width of the line drawn through the points corresponds to the difference in rotational energies and is thus a measure of the expected difference between the ${ }^{3} \mathrm{He}$ and ${ }^{4} \mathrm{He}$ points. Although the experimental points do scatter somewhat more than expected from the estimated uncertainties it does appear that the $\mathrm{T}_{\gamma}$ values from the ${ }^{4} \mathrm{He}$ experiments are slightly larger than those from the ${ }^{3} \mathrm{He}$ ones, in agreement with the theoretical estimate. Our conclusion is that the reactions leading to ${ }^{137 \mathrm{~m}} \mathrm{Ce}$ also confirm the independence hypothesis.

A more sensitive test of the relation between angular momentum and energy dissipated in photon emission than is afforded by the data in Fig. 5 can be obtained from a comparison of the $T_{n}$ or $T_{\gamma}$ values associated with the formation of ${ }^{137 m_{C e}}$ and ${ }^{137 g_{C e}}$ in the same reaction. As indicated in Fig. 3, the differences between $\left\langle\mathrm{J}_{c}^{\mathrm{m}}\right\rangle$ and $\left\langle\mathrm{J}_{\mathrm{c}}^{\mathrm{g}}\right\rangle$ for a given projectile range from 3 to $10 \mathrm{t}$ units so that the expected effect is much larger. As before, the expected difference in photon energies is obtained by application of Eq. 6 to the data shown in Fig. 3. The experimental values of $\Delta \mathrm{T}_{\gamma}$ are obtained by direct subtraction of the $\mathrm{T}_{\gamma}$ values for ${ }^{137 g} \mathrm{Ce}$ from those for ${ }^{137 \mathrm{~m}} \mathrm{Ce}$ at the same bombarding energy. The results are shown in Fig. 6. Because of the very small difference in $Q$ values for the formation of ${ }^{137 m_{C e}}$ and ${ }^{137 g_{C e}}$, the experimental points are plotted at the average value of $\mathrm{E}_{\mathrm{cm}}+Q$. Within the rather large uncertainties introduced by the subtraction of $T_{\gamma}$ values, the experimental points are in satisfactory agreement with the theoretical curve. 


\section{REFERENCES}

1. D. M. Montgomery and N. T. Porile. (Preceeding paper).

2. S. N. Ghoshal, Phys. Rev. 80, 939 (1950).

3. N. T. Porile, S. Tanaka, H. Amano, M. Furukawa, S. Iwata, and M. Yagi, Nucl. Phys. $\underline{43}, 500$ (1963).

4. J. M. D'Auria, J. J. Fluss, G. Herzog, L. Kowalski, J. M. Miller and R. C. Reedy, Phys. Rev. 174, 1409 (1968).

5. G. N. Simonoff and J. M. Alexander, Phys. Rev. 133, B105 (1964).

6. M. Kaplan and V. Subrahmanyam, Phys. Rev. 153, 1186 (1967).

7. N. T. Porile and G. B. Saha, Phys. Rev. 158, 1027 (1967).

8. I. Fujiwara and N. T. Porile, Phys. Rev. 173, 1055 (1968).

9. Obtained from Oak Ridge National Laboratory.

10. W. Parker and A. Falk, Nucl. Instr. Methods, 49,220 (1967).

11. C. F. Williamson, J. Boujot, and J. Picard, Table of Range and Stopping Power of Chemical Elements for Charged Particles of Energy 0.05-550 MeV. CEA-R 3042 (1966).

12. D. G. Swanson and N. T. Porile (aukmitted to Nucl. Phys.).

13. D. G. Swanson and N. T. Porile (submitted to Nucl. Phys.).

14. J. H. E. Mattauch, W. Thiele, and A. H. Wapstra, Nucl. Phys. 131, A119 (19:68). 
TABLE I

Values of Quantities Derived from Angular Distributions

$$
{ }^{136} \mathrm{Ba}\left({ }^{4} \mathrm{He}, 3 \mathrm{n}\right){ }^{137} \mathrm{Ce}
$$

\begin{tabular}{|c|c|c|c|c|c|c|}
\hline Isomer & $\begin{array}{l}\text { Bombarding } \\
\text { Energy } \\
(\mathrm{MeV})\end{array}$ & $\begin{array}{l}\mathrm{E}_{\mathrm{CM}}+\mathrm{Q} \\
(\mathrm{MeV})\end{array}$ & $\begin{array}{l}\left\langle\theta_{L}\right\rangle \\
(\operatorname{deg})\end{array}$ & $<\tan ^{2} \theta_{L}>$ & $\underset{n}{T_{n}}$ & $\stackrel{\mathrm{T}_{\mathrm{Y}}}{(\mathrm{MeV})}$ \\
\hline $\begin{array}{l}\mathrm{m} \\
\mathrm{g}\end{array}$ & $\begin{array}{l}43.6 \\
43.6\end{array}$ & $\begin{array}{l}17.4 \\
17.7\end{array}$ & $\begin{array}{l}11.3 \\
12.4\end{array}$ & $\begin{array}{l}.0574 \\
.0673\end{array}$ & $\begin{array}{l}14.0 \pm .3 \\
16.2 \pm .8\end{array}$ & $\begin{array}{l}3.4 \pm .3 \\
1.5 \pm .8\end{array}$ \\
\hline $\begin{array}{l}\mathrm{m} \\
\mathrm{g}\end{array}$ & $\begin{array}{l}41.3 \\
41: 3\end{array}$ & $\begin{array}{l}15.2 \\
15.5\end{array}$ & $\begin{array}{l}10.8 \\
11.7\end{array}$ & $\begin{array}{l}.0522 \\
.0603\end{array}$ & $\begin{array}{l}12.1 \pm .2 \\
13.8 \pm .7\end{array}$ & $\begin{array}{l}3.1 \pm .2 \\
1.7 \pm .7\end{array}$ \\
\hline m & $\begin{array}{r}39.2 \\
.39 .2\end{array}$ & $\begin{array}{l}13.2 \\
13.5\end{array}$ & $\begin{array}{l}10.0 \\
10.8\end{array}$ & $\begin{array}{l}.0437 \\
.0503\end{array}$ & $\begin{array}{r}9.7 \pm .1 \\
11.1 \pm .6\end{array}$ & $\begin{array}{l}3.5 \pm .1 \\
2.4 \pm .6\end{array}$ \\
\hline $\begin{array}{l}\mathrm{m} \\
\mathrm{g}\end{array}$ & $\begin{array}{l}39.1 \\
39.1\end{array}$ & $\begin{array}{l}13.1 \\
13.4\end{array}$ & $\begin{array}{l}10.8 \\
11.0\end{array}$ & $\begin{array}{l}.0534 \\
.0542\end{array}$ & $\begin{array}{l}11.7 \pm .2 \\
11.9 \pm .6\end{array}$ & $\begin{array}{l}1.4 \pm .2 \\
1.5 \pm .6\end{array}$ \\
\hline $\begin{array}{l}\mathrm{m} \\
\mathrm{g}\end{array}$ & $\begin{array}{l}39.0 \\
39.0\end{array}$ & $\begin{array}{l}12.9 \\
13.2\end{array}$ & $\begin{array}{l}10.1 \\
10.5\end{array}$ & $\begin{array}{l}.0446 \\
.0466\end{array}$ & $\begin{array}{r}9.8 \pm .2 \\
10.2 \pm .5\end{array}$ & $\begin{array}{l}3.1 \pm .2 \\
3.0 \pm .5\end{array}$ \\
\hline $\begin{array}{l}\mathrm{m} \\
\mathrm{g}\end{array}$ & $\begin{array}{l}36.1 \\
36.1\end{array}$ & $\begin{array}{l}10.2 \\
10.5\end{array}$ & $\begin{array}{r}9.8 \\
10.1\end{array}$ & $\begin{array}{l}.0421 \\
.0442\end{array}$ & $\begin{array}{l}8.6 \pm .2 \\
9.0 \pm .5\end{array}$ & $\begin{array}{l}1.6 \pm .2 \\
1.5 \pm .5\end{array}$ \\
\hline $\begin{array}{l}\mathrm{m} \\
\mathrm{g}\end{array}$ & $\begin{array}{l}33.3 \\
33.3\end{array}$ & $\begin{array}{l}7.5 \\
7.8\end{array}$ & $\begin{array}{r}9.5 \\
10.1\end{array}$ & $\begin{array}{l}.0390 \\
.0434\end{array}$ & $\begin{array}{l}7.5 \pm .2 \\
7.8 \pm .4\end{array}$ & $\begin{array}{l}0.0 \pm .2 \\
0.0 \pm .3\end{array}$ \\
\hline
\end{tabular}

$$
{ }^{137} \mathrm{Ba}\left({ }^{3} \mathrm{He}, 3 \mathrm{n}\right){ }^{137} \mathrm{Ce}
$$

$\begin{array}{lllllll}\mathrm{m} & 32.5 & 20.5 & 16.0 & .1284 & 16.4 \pm .3 & 4.1 \pm .3 \\ \mathrm{~g} & 32.5 & 20.8 & 16.9 & .1440 & 18.2 \pm .7 & 2.6 \pm .9 \\ \mathrm{~m} & 28.0 & 16.1 & 15.4 & .1187 & 13.2 \pm .3 & 2.9 \pm .3 \\ \mathrm{~g} & 28.0 & 16.4 & 16.2 & .1336 & 14.7 \pm .7 & 1.7 \pm .7 \\ \mathrm{~m} & 27.8 & 15.9 & 15.1 & .1164 & 12.9 \pm .3 & 3.0 \pm .3 \\ \mathrm{~g} & 27.8 & 16.2 & 15.3 & .1174 & 13.0 \pm .6 & 3.2 \pm .6 \\ \mathrm{~m} & 27.6 & 15.8 & 15.5 & .1202 & 13.2 \pm .3 & 2.6 \pm .3 \\ \mathrm{~g} & 27.6 & 16.1 & 16.1 & .1315 & 14.3 \pm .7 & 1.8 \pm .7 \\ \mathrm{~m} & 24.3 & 12.5 & 15.7 & .1213 & 11.7 \pm .1 & 0.8 \pm .2 \\ \mathrm{~g} & 24.3 & 12.8 & 15.9 & .1242 & 11.9 \pm .6 & 0.9 \pm .6 \\ \mathrm{~m} & 20.3 & 8.6 & 15.0 & .1059 & 8.6 \pm .2 & 0.0 \pm .4 \\ \mathrm{~g} & 20.3 & 8.9 & 15.2 & .1082 & 8.8 \pm .4 & 0.1 \pm .4\end{array}$


TABLE II

Average Angular Momentum of Compound Nuclei ${ }^{a}$

Leading to ${ }^{137 \mathrm{~m}_{\mathrm{Ce}}}$ and ${ }^{137 \mathrm{~g}_{\mathrm{Ce}}}$

Method of Calculation ${ }^{b}$

$\left\langle\mathrm{J}_{\mathrm{C}}^{\mathrm{m}}\right\rangle\left\langle\mathrm{J} \mathrm{C}^{\mathrm{g}}\right\rangle$

Method 1

$13.5 \quad 2.4$

Method 2

11.92 .5

Method 3

$10.0 \quad 2.5$

a. The compound nucleus is formed in 4 He bombardment with an excitation energy of $42.8 \mathrm{MeV}$.

b. See text for explanation. 
FIGURE CAPTIONS

Fig. 1 Dependence of the angular distribution of ${ }^{137 m} \mathrm{Ce}$ from the $\left({ }^{4} \mathrm{He}, 3 \mathrm{n}\right)$ reaction on target thickness and collimator size. $\mathrm{O}=39.0 \mathrm{MeV}$, $0.32 \mathrm{~cm}$ collimator, and $10.0 \mu \mathrm{gm} / \mathrm{cm}^{2}$ target; $\Delta-39.2 \mathrm{MeV}, 0.32 \mathrm{~cm}$ collimator and $5.5 \mu \mathrm{gm} / \mathrm{cm}^{2}$ target; $\mathrm{x}-39.0 \mathrm{MeV}, 0.16 \mathrm{~cm}$ collimator, and $12.0 \mu \mathrm{gm} / \mathrm{cm}^{2}$ target. The curves are normalized to the same area.

Fig. 2 Average recoil angles of ${ }^{137 m, m_{\mathrm{Ce}}}$ from the $\left({ }^{3} \mathrm{He}, 3 \mathrm{n}\right)$ and $\left({ }^{4} \mathrm{He}, 3 \mathrm{n}\right)$ reactions. The circles refer to ${ }^{137 \mathrm{~g}} \mathrm{Ce}$ and triangles to ${ }^{137 \mathrm{~m}} \mathrm{Ce}$.

Fig. 3 Approximate values of the average angular momentum of compound nuclei leading to ${ }^{137 \mathrm{~m}} \mathrm{Ce}$ and ${ }^{137 \mathrm{~g}_{\mathrm{Ce}}}$. The circles refer to ${ }^{4} \mathrm{He}$ induced reactions and triangles to ${ }^{3}$ He induced reactions. Open symbols. show compound nuclei leading to ${ }^{137 \mathrm{~m}} \mathrm{Ce}$ and shaded symbols

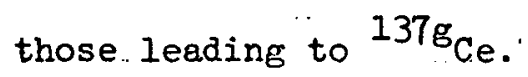

Fig. 4 Comparison of $T_{n}$ and $T_{\gamma}$ for ${ }^{137 . g} \mathrm{Ce}$ from $\left({ }^{4} \mathrm{He}, 3 n\right)$ and $\left({ }^{3} \mathrm{He}, 3 n\right)$ reactions. Triangles represent ${ }^{3} \mathrm{He}$ and circles the ${ }^{4} \mathrm{He}$ reactions. Open symbols refer to $\mathrm{T}_{\mathrm{n}}$ and shaded symbols to $\mathrm{T}_{\gamma}$.

Fig. 5 Comparison of $T_{n}$ and $T_{\gamma}$ for ${ }^{137 m_{C e}}$ from the $\left({ }^{4} \mathrm{He}, 3 n\right)$ and $\left({ }^{3} \mathrm{He}, 3 n\right)$ reactions. Symbols have same meaning as in Fig. 4. The widths of the lines drawn through the points correspond to the expected differences between 4 He and $3_{H e}$ rosotions.

Fig. 6 Differences between $\mathrm{T}_{\gamma}$ for reactions leading to $137 \mathrm{~m} \mathrm{Ce}$ and

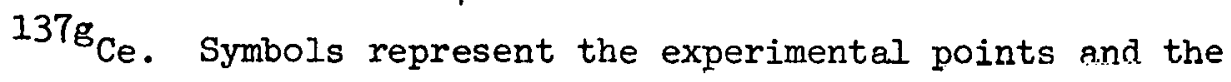
solid line is from the theoretical calculation. 


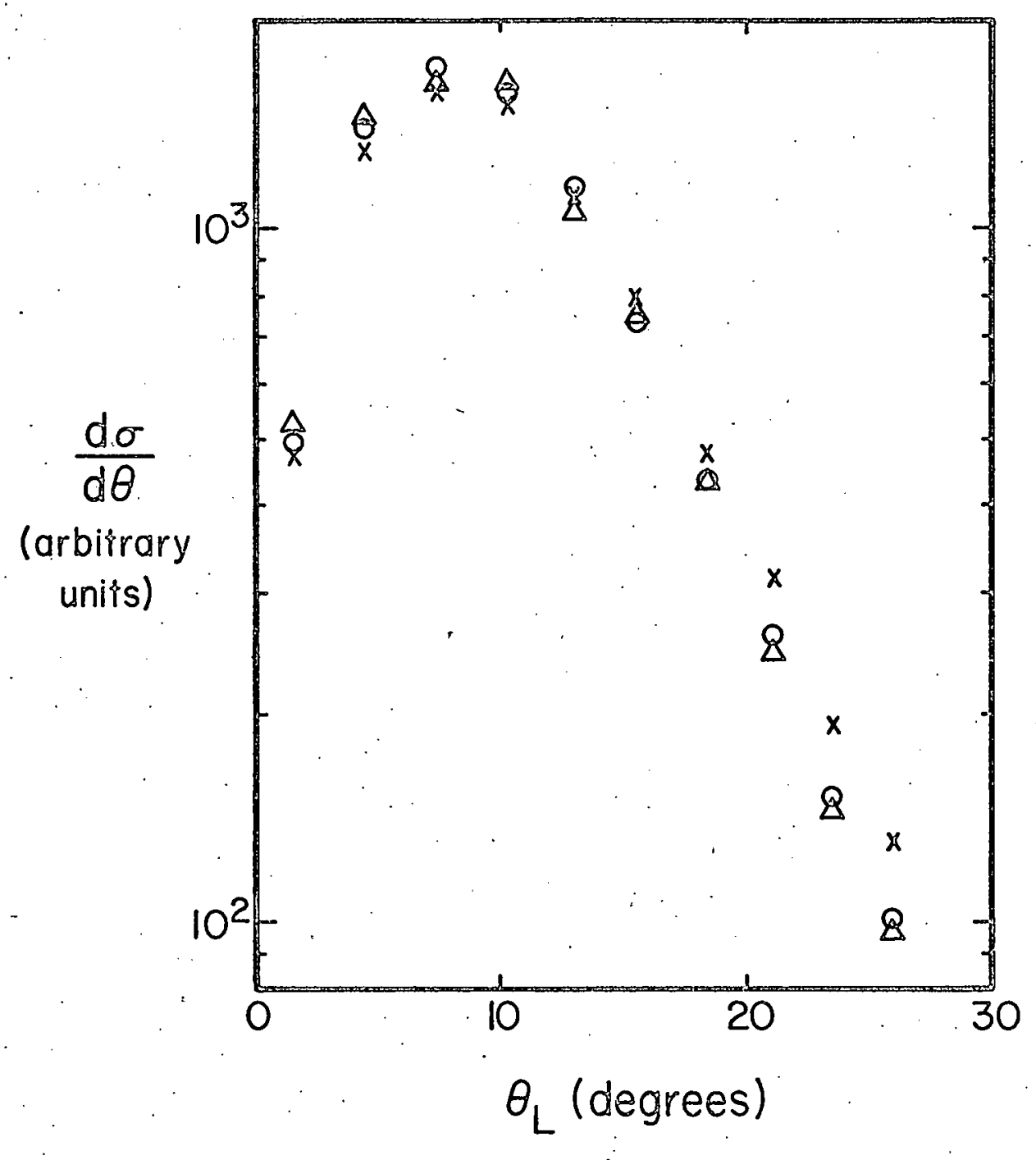



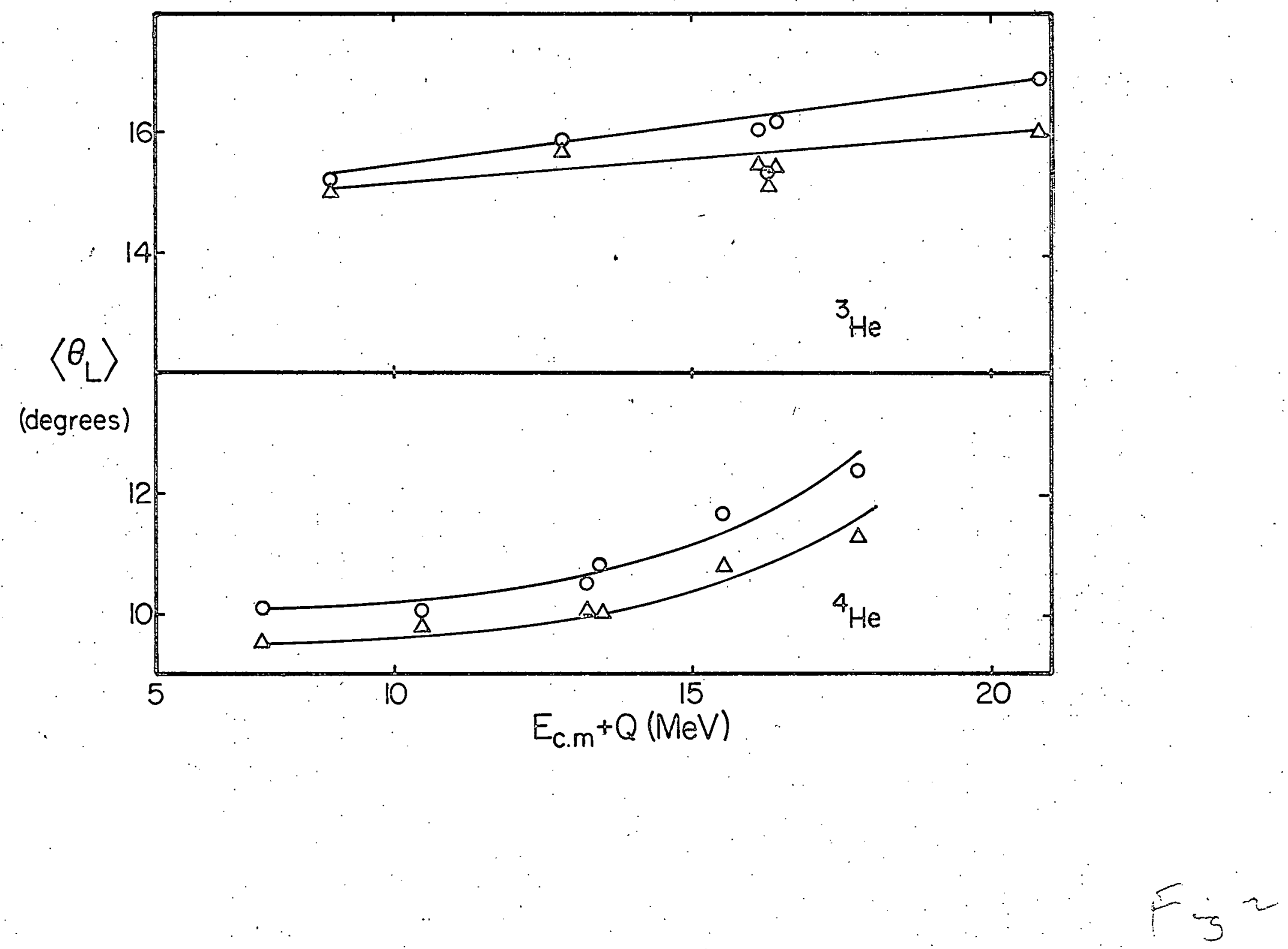


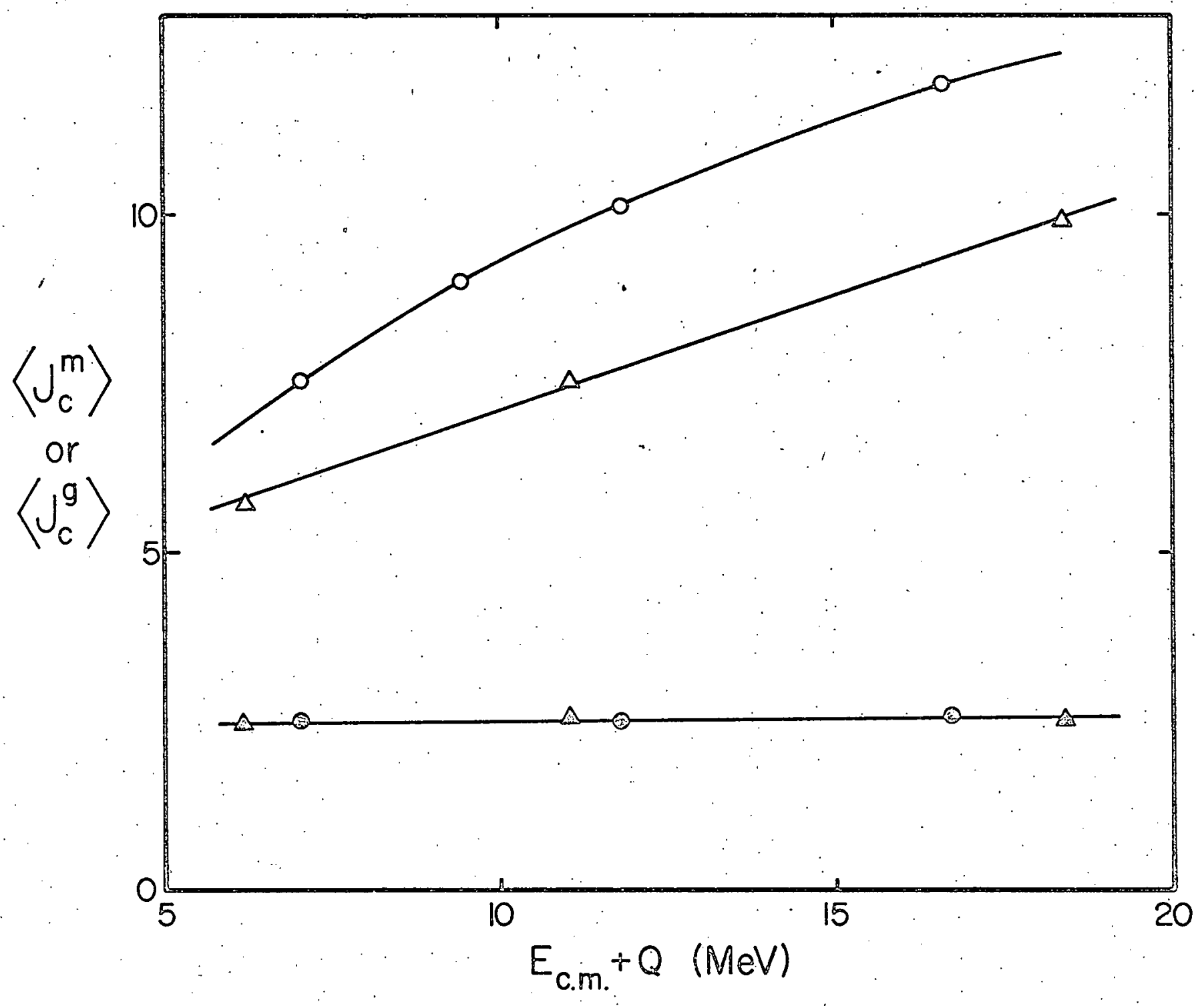

$\mathrm{Fis}^{3}$ 


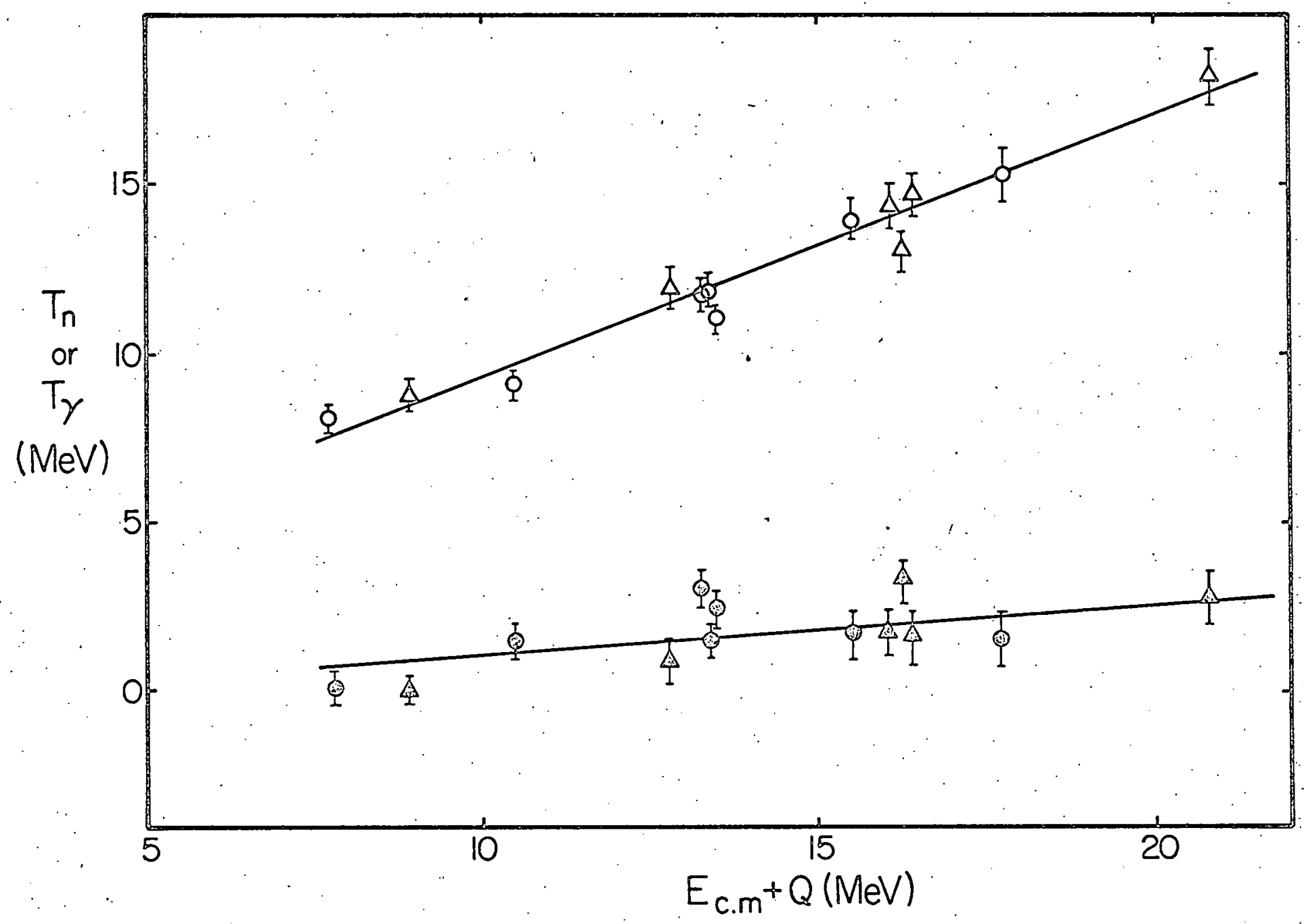




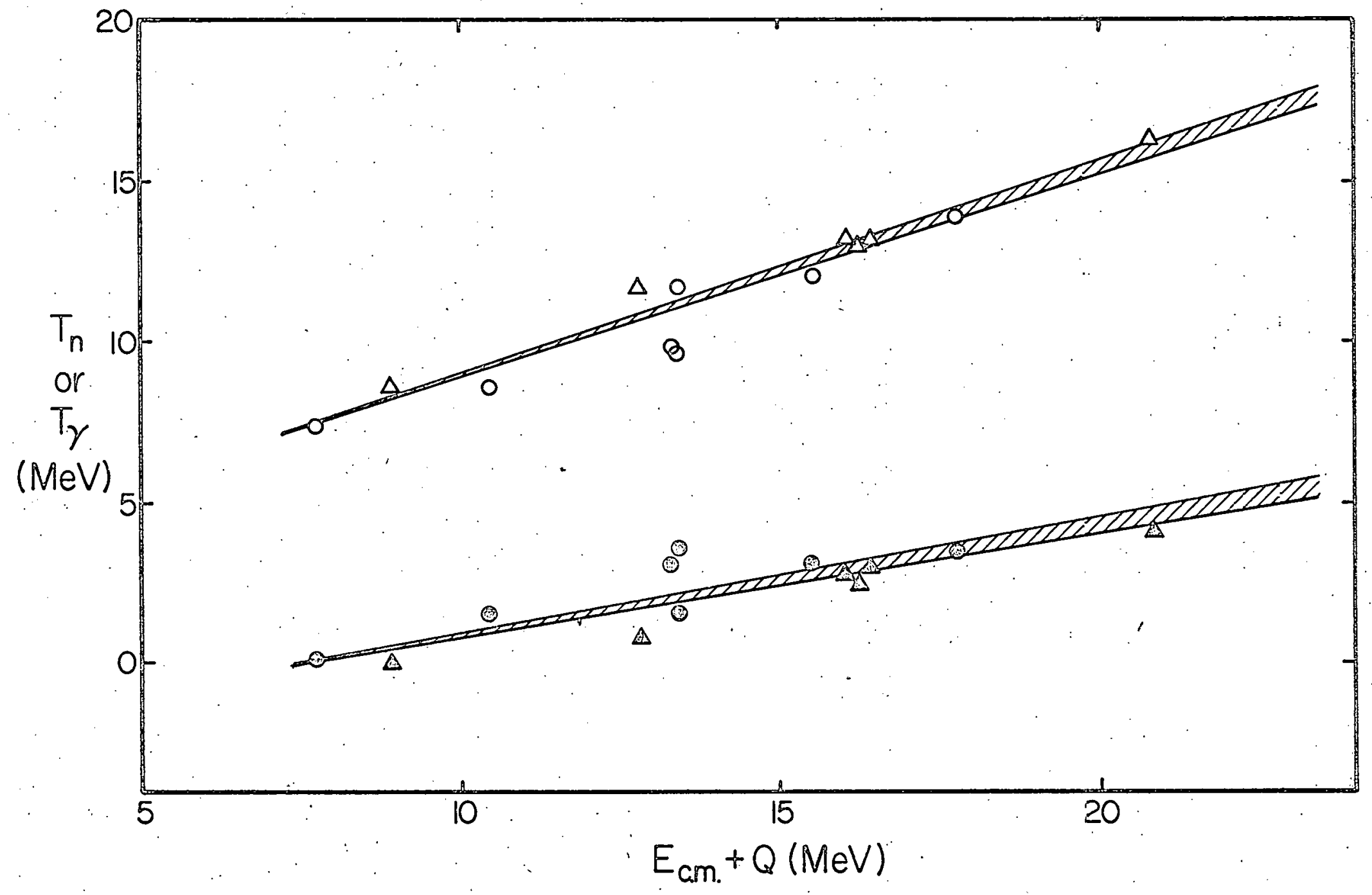




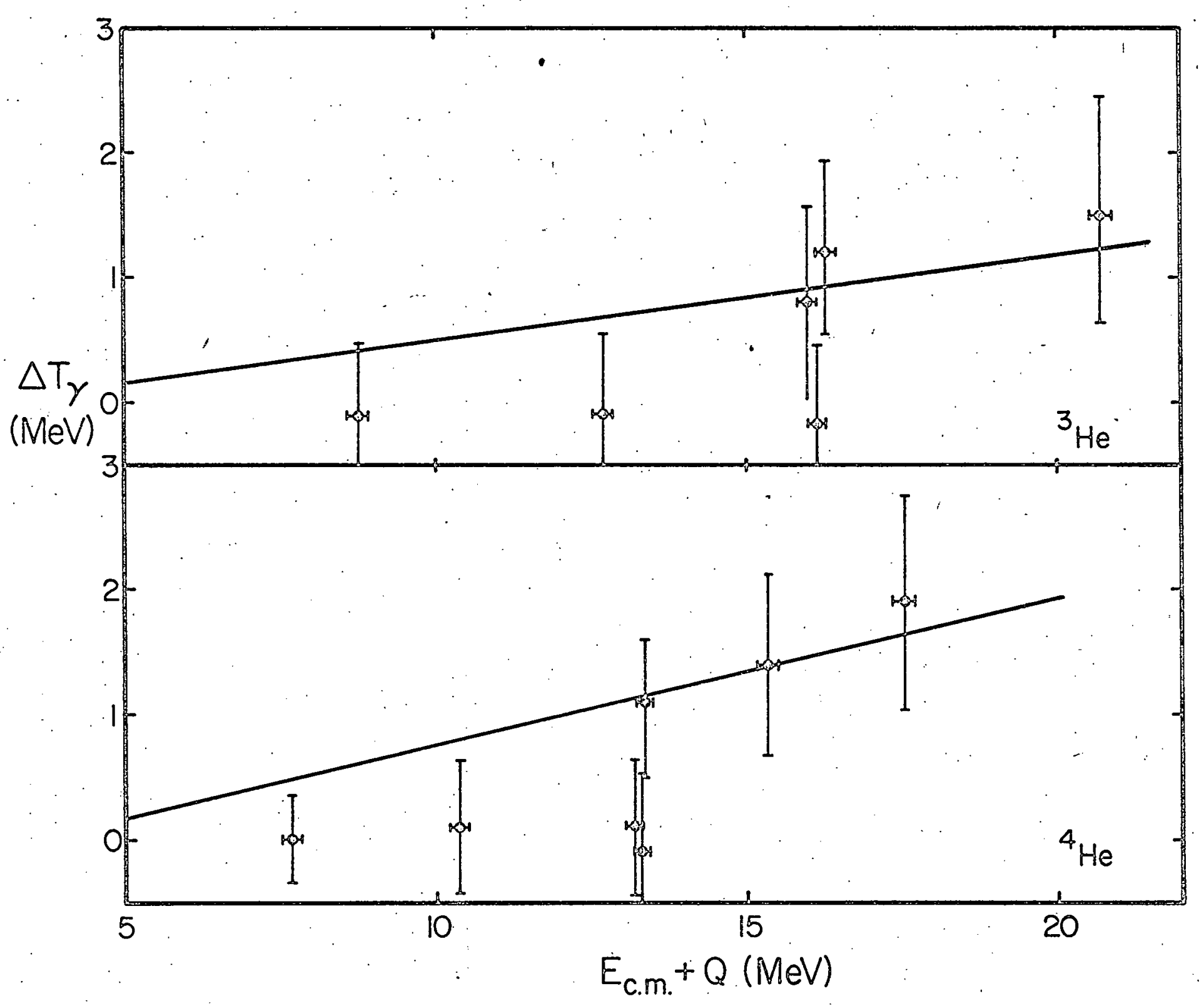

Fs 